\title{
O PATRIMÔNIO CULTURAL E O PÓS-COLONIAL: NOTAS \\ ETNOGRÁFICAS SOBRE UMA OCUPAÇÃO ARTÍSTICA NO CENTRO HISTÓRICO DE RIO DE CONTAS-BA
}

\author{
Jean Pierre Pierote Silva ${ }^{1}$
}

\section{Introdução}

O patrimônio cultural nas suas diversas formas - monumentos, paisagens, celebrações, formas de expressão, saberes e fazeres, coleções, etc. - representa alegoricamente valores de excepcionalidade, de autenticidade e de relevância histórica. Além disso, ele também pode representar uma poderosa narrativa sobre a "identidade" nacional, de modo que o processo de tombamento, ou de registro, geralmente são efetuados quando um bem cultural representam expressões artísticas e históricas entendidas como relevantes para um grupo social, ou para a nação (Gonçalves, 1996; Lima Filho, 2009).

Monumentos públicos e religiosos em pedra, casario em adobe e igrejas barrocas compõem a paisagem urbana de Rio de Contas, cidade localizada ao sul da Chapada Diamantina no estado da Bahia. Em 1980, essa cidade recebeu o título de Patrimônio Nacional pelo Instituto do Patrimônio Histórico e Artístico Nacional (IPHAN). O título foi concedido em razão da excepcionalidade histórica, paisagística, etnográfica e artística de suas edificações, cujas construções datam da segunda metade do século XVIII e início do XIX (Pierote Silva, 2014).

Rio de Contas, pequena cidade do Alto Sertão baiano, fundada para ser sede administrativa e financeira da região no século XVIII, carrega em seu corpo as marcas as cicatrizes do processo de colonização, onde a arquitetura é preservada por ser testemunha da narrativa histórica oficial que nos informa sobre o processo de colonização vivenciado pelo Estado-nação brasileiro. Nesse sentido, o fato de Rio de Contas ter sido patrimonializada pelo órgão regulador do Patrimônio Histórico e Artístico Nacional, o IPHAN, significa que o Estado-nação brasileiro entende como relevante a preservação de algumas edificações dessa cidade.

\footnotetext{
${ }^{1}$ Universidade Federal de Goiás, Brasil.
} 
Os monumentos, para Riegl (2006), são criações humanas possuidoras de algumas finalidades. Lembrar às gerações futuras de alguns fatos, ações, distinções, ou a combinação desses fatores são alguns exemplos da intencionalidade que um monumento pode ter. Em Rio de Contas, os primeiros monumentos a serem patrimonializados foram justamente aqueles que representam o poder colonial. Igrejas católicas, Casa de Câmara e Cadeia, casas de Barões e coronéis, foram as edificações que primeiramente receberam o titulo de patrimônio cultural ${ }^{2}$. A relevância histórica é um dos critérios avaliativos nos processos de patrimonialização, entretanto, resta saber de qual história os monumentos do poder colonial são testemunhas.

Não temos dúvida de que essa história é a da dominação econômica, política e cultural de um grupo por outros. Nesse sentido, a escolha de alguns bens culturais como patrimônio também significa à legitimação, por meio das cicatrizes materiais, da memória oficial e dos valores de um determinado grupo social. De modo que o patrimônio cultural, assim compreendido, também atua nas relações de poder que reificam hierarquias e a dominação de um grupo social.

Considerando a diversidade de sentidos que a categoria patrimônio cultural pode ter, o objetivo desse artigo é o de pensar, por meio de uma perspectiva pós-colonial, as relações entre o patrimônio cultural edificado e os modos de habitar a cidade, tomando como base a minha experiência de pesquisa de campo etnográfica em uma residência artística na cidade de Rio de Contas em 2013.

Essa é a principal questão que impulsiona as reflexões presentes nesse trabalho. Partindo das experiências vivenciadas durante a realização de uma pesquisa de campo etnográfica em uma residência artística, que resultou em uma ocupação artística do Largo do Rosário, no centro histórico patrimonializado de Rio de Contas, esse artigo se propõe a pensar como uma política dos afectos $^{3}$ e das artes pode contribuir metodologicamente para a construção de um conhecimento que não esteja aprisionado nas representações, na materialização de identidades e que consiga comunicar a experiência etnográfica também pela ordem do sensível.

\footnotetext{
2 Em 1958, a Igreja Matriz do Santíssimo Sacramento e a Igreja de Sant'Ana foram tombadas isoladamente pelo Instituto do Patrimônio Histórico e Artístico Nacional. Em 1959, o antigo Paço Municipal, atual Fórum, também foi incluído no Livro de Tombo. Somente em 1980 o conjunto arquitetônico da cidade foi considerado Patrimônio Nacional.

${ }^{3}$ Baseada na filosofia de Deleuze e Guattari (1992), a noção de afecto que aqui utilizo é pensada como um conjunto de sensações e percepções que são capazes de produzir afecções em um corpo, ou seja, alterar e transforma-los, podendo essa transmutação produzir o aumento ou a diminuição da potência de agir deste corpo no mundo.
} 
Ao me valer do termo pós-colonial, o faço me apropriando da ideia defendida por Hall (2009:101), em que o pós-colonial é pensado como um conceito descritivo e não avaliativo. Descritivo no sentido de "caracterizar a mudança nas relações globais, que marca a transição (necessariamente irregular) da era dos impérios para o momento da pós-independência ou da pós-colonização" (Hall, 2009:101). Não se trata de uma descrição de uma sociedade ou período histórico, mas sim de uma releitura da colonização como um processo global, transnacional e transcultural.

Essa perspectiva, que pode desloca e descentraliza narrativas imperiais do passado, não diz respeito ao um tempo cronológico. O pós-colonial, nesse aspecto, se propõe a "ir além" do colonial, não sendo portanto "posterior" ao colonial. Sobre o que falam as narrativas relacionadas aos monumentos edificados do período histórico colonial em Rio de Contas? Em termos de materialidade, falam sobre os "rastros", sobre os "vestígios" do processo de colonização vivenciado pelo Estado-nação.

Porém, os sentidos atribuídos a estes monumentos não são fixos, levando em consideração o fato de que os moradores dessa cidade atribuem sentido a sua experiência humana no mundo, em decorrência principalmente pela troca existente entre o mundo sensível e o mundo das significações (Eckert e Rocha, 2006).

A cidade antiga, dos casarões imponentes, ruas largas, calçadas alinhadas, igrejas monumentais foi descrita pelo antropólogo estadunidense Marvin Harris (1956) como cenário povoado por um ethos urbano. O estudo de comunidade desenvolvido por Harris (1956) em Rio de Contas, na década de cinquenta do século XX, foi motivado pelo convênio entre o Estado da Bahia e a Universidade de Columbia. Nesse estudo, o principal objetivo era investigar os processos de transformação social na região, as relações raciais e as diferenciações entre o urbano e o rural no Brasil.

A razão pela qual Rio de Contas foi uma das cidades escolhidas para ser pesquisada pelo convênio entre o Estado da Bahia e a Universidade de Columbia merece atenção. Segundo Guaraná de Castro (2001), um dos motivos que atraiu Harris (1956) para Rio de Contas foi a impressão de que a cidade havia parado de mudar em uma região onde estavam ocorrendo várias transformações sociais, econômicas, culturais e paisagísticas. Harris relata que uma das características mais marcantes do modo de vida dos moradores da cidade estava nos resquícios de um modo de vida aristocrático presentes em um grupo social identificado pelo autor como "A" (brancos ricos). 
Para Harris, a cena urbana em Rio de Contas contrastava com os modos de vida da população da zona rural do município. A oposição entre cidade e campo em Rio de Contas era tão demarcada que a distância geográfica entre as comunidades rurais e o núcleo urbano do município não eram suficientes para explicar a definição de duas subculturas tão fortes (Guaraná de Castro, 2001:201).

$\mathrm{O}$ fato de essa cidade ter sido patrimonializada e descrita por Harris como possuidora de um ethos urbano também instigou o meu interesse de pesquisa em investigar as formas como os moradores de Rio de Contas habitavam e se relacionavam com o espaço urbano da cidade. Desse modo, Rio de Contas foi-se constituindo nessa pesquisa, por uma perspectiva pós-colonial, como um rico campo de investigação no que diz respeito às questões do patrimônio cultural, da mudança e da continuidade da paisagem urbana.

A cidade da oculta mudança, onde o tempo age, mas os efeitos das transmutações temporais devem ser apaziguados, em que se preserva o passado na construção do presente. O passado, o acontecido que dura no constante processo de atualização das experiências do agora. O passado da colonização, do ouro, do diamante, dos bandeirantes, coronéis, barões, bacharéis, dos índios dizimados e dos negros escravizados. Políticas públicas que preservam edificações desse período pela excepcionalidade histórica, arquitetônica e artística.

\section{Árvores em queda}

Nos últimos dez anos, Rio de Contas tem abrigado diversos projetos artísticos e culturais. Festivais de arte, música, residências artísticas e exposições passaram a movimentar a cena artística da cidade, criando um cenário de interação entre artistas de Rio de Contas com os de outras regiões. Grande parte desses projetos surgiu de parcerias realizadas entre o Espaço Imaginário ${ }^{4}$, espécie de centro cultural/produtora inaugurado em junho de 2011, com produtores culturais locais.

O Espaço Imaginário é dirigido por um casal de artistas/produtores culturais que vive em Rio de Contas desde 2010. Da relação entre os artistas do Espaço Imaginário e cidade, algumas afectos surgiram. Porém, me deterei aqui a falar sobre o afecto que

\footnotetext{
${ }^{4}$ Disponível em: $<$ https://espacoimaginarioriodecontas.wordpress.com/>.
} 
resultou em um projeto de residência e de ocupação artística do Largo do Rosário, um grande campo gramado rodeado por edificações históricas, situado no perímetro tombado de Rio de Contas.

Além de ser um lugar de encontro das principais ruas do centro histórico, no Largo do Rosário também estão localizadas importantes edificações da cidade, como o Teatro São Carlos e o prédio da Prefeitura Municipal. Porém, o que mais sensibilizou estes artistas não foram somente as edificações históricas que cercam o Largo do Rosário, mas sim o aparente vazio daquele lugar. Não havia nenhuma sombra, apenas luminosidade.

No passado, várias árvores habitavam o Largo, mas foram derrubadas misteriosamente, durante uma madrugada, no final dos anos 1980. Os responsáveis nunca assumiram oficialmente o ato, porém, a existência delas ainda ressoa na memória dos moradores da cidade, como relatou uma interlocultora dessa pesquisa, moradora da cidade e pesquisadora da área ambiental:

Existem vários debates, por exemplo, sobre essa lei de visibilidade do patrimônio, que a gente tem pouco acesso e que diz que determinadas construções não podem atingir certo nível de altura, por que empata a visibilidade do casario. Com base nessa lei a gente teve um conflito em relação às árvores que foram derrubadas ali no Largo do Rosário, porque ali existia um pé de amêndoas, existiam seringueiras, depois que essas árvores foram derrubadas no calar da madrugada, isso nos levou a refletir sobre quem seria o responsável por essa ação, por que derrubaram essas árvores? Foi o IPHAN pela lei da visibilidade? Em conversas internas com algumas pessoas do IPHAN, questionamos isso e eles responderam que só tinha sido uma sugestão, que seria para dar mais visibilidade ao patrimônio, e o prefeito na época entendeu da forma dele e acabou derrubando as árvores, então a coisa nunca ficaram muito claras, até hoje não sabemos o que aconteceu [...]. Por que a gente tem um casario histórico lindíssimo tombado, casas lindas aqui no centro e que se o IPHAN não existisse talvez elas não existiriam mais. Na verdade é uma questão de equilíbrio. Viver o presente, respeitando o passado e também tentando adaptar com a modernidade, inclusive com as árvores, que é uma questão de sobrevivência (Interlocutora da pesquisa e pesquisadora da área ambiental).

Nessa narrativa, percebemos que o mistério em relação à derrubada das árvores do Largo do Rosário levanta também outras questões importantes no que diz respeito à relação entre as políticas de patrimônio e os fluxos da vida na cidade. A forma como a agência reguladora do patrimônio e o poder municipal agiram no espaço urbano demonstra que a visibilidade do patrimônio, para essas instituições, é mais importante do que a apropriação e o bem-estar da população em relação aos espaços públicos da cidade. 
Durante a pesquisa de campo, alguns moradores do Largo me relataram que ali já existiu uma igreja dedicada à Nossa Senhora do Rosário dos Pretos. Disseram também que lá havia uma lagoa, mas que esta foi aterrada, havia uma aldeia indígena, no período pré-colonial e também foi local de um acampamento cigano. Desse modo, o grande espaço, aparentemente vazio, sem árvores, cercado apenas pelas edificações do centro histórico da cidade, é também um lugar de memória (Nora, 1985) para os moradores de Rio de Contas.

\section{O Largo Jardim}

Mas o que existe na superfície do Largo do Rosário? Além do acontecido, das marcas e dos signos da memória, o que existe nesse lugar? Voltamos para o afecto dos artistas do Espaço Imaginário que, no gramado vazio do lugar, enxergaram uma superfície para a composição artística. Assim surgiu o Largo Jardim, proposta de residência artística produzida pelo Espaço Imaginario, premiada pelo Calendário das Artes da Fundação Cultural do Estado da Bahia (Funceb) do Governo da Bahia e pelo Edital Microprojetos Mais Cultura Rio São Francisco da Fundação Nacional de Artes (Funarte)/Ministério da Cultura, em 2013.

Em janeiro de 2013, onze artistas foram convidados para participar dessa residência, dentre eles, eu. Desde 2007, desenvolvo trabalhos na fronteira entre a antropologia e as artes visuais, utilizando principalmente a fotografia como linguagem. Além do meu interesse artístico, também tinha interesse etnográfico em participar residência, pois ela ocorreu no momento em que eu realizava pesquisa de campo etnográfico em Rio de Contas, que resultou na dissertação de mestrado intitulada Deslocamentos Patrimoniais: polifonias, memórias e visualidades em Rio de Contas BA, defendida em 2014 no Programa de Pós-graduação em Antropologia Social da Universidade Federal de Goiás (UFG).

Durante a primeira semana da residência, realizamos exercícios de composição em tempo real baseados na proposta do coreógrafo João Figueiredo (2012) e da antropóloga Fernanda Eugênio (2012), autores que pensam a composição como um "pôr-se com" o outro, onde a posição de cada agente é dada pela relação com os demais (Gibson, 1979). Nessa proposta, a criação é pensada no lugar da renúncia ao controle, 
quando nos colocamos disponíveis como ferramentas e encontramos aquilo que não buscávamos, o acontecimento.

Para Deleuze e Guattari (21992), o acontecimento é da ordem do imaterial, incorpóreo, não temporal e não espacialmente ordenável. Já a ciência está preocupada em actualiza os estados de coisas num corpo, num tempo e num espaço, ou seja, em um plano de referência. A ciência não se ocupa do acontecimento, pois ela está voltada para o mundo empírico. Já a arte não tem por ocupação ordenar o estado de coisas, mas ela trabalha no estado de coisas para fazer surgir acontecimentos e transforma-los em sensações.

De certa forma, os artistas participantes do Largo Jardim trabalhavam na criação um plano para a composição das ações que resultaria da ocupação artística do Largo do Rosário não para atualizar os estados de coisas, mas para tornar sensível fragmentos do acontecimento. Em função de meu mestrado, fui para campo com um projeto de pesquisa voltado para as questões da memória coletiva (Halbwachs, 2006), do imaginário (Durand, 2007) e do patrimônio cultural (Gonçalves, 1996; Lima Filho, 2009; Tamaso, 2012). Mas as principais questões do coletivo, postas após essa primeira semana de trabalho, eram: o que existe no Largo do Rosário encoberto pelo véu do que achamos obviamente existir? O que há que não reparamos, nesse Largo vazio?

O meu conflito como pesquisador estava instalado na tensão entre a prática artística e a prática da ciência. O meu objetivo como etnógrafo, enviesado principalmente pelos manuais clássicos do método etnográfico, apontava como caminho mais seguro a realização de uma "arqueologia" da memória do Largo do Rosário, pois assim eu acreditava poder adentrar nas camadas das representações do lugar. Porém, essa não era a proposta do Largo Jardim, as forças que atravessavam os outros artistas pareciam se enfraquecer quando atravessadas pelas linhas da historicidade, pois o que importava era criar blocos de sensações na superfície do Largo do Rosário. Parecia haver um recuo, um engessamento poético da criação perante o acontecido.

Nesse momento, acredito ter vivenciado algo semelhante que ocorreu com Favret-Saada (2005), antropóloga que realizou pesquisa sobre a feitiçaria no Bocage francês e que foi confundida localmente com uma pessoa que quebra encantos, uma “desenfeitiçadora". Sobre o "observar", o "participar”, a "observação participante” e o "ser afetado", Favret-Saada (2005) pontuou algumas considerações sobre as contradições destes termos na prática etnográfica: 


\begin{abstract}
No começo, não parei de oscilar entre esses dois obstáculos: se eu "participasse", o trabalho de campo se tornaria uma aventura pessoal, isto é, o contrário de um trabalho; mas se tentasse "observar", quer dizer, manter-me a distância, não acharia nada para "observar". No primeiro caso, meu projeto de conhecimento estava ameaçado, no segundo, arruinado. Embora, durante a pesquisa de campo, não soubesse o que estava fazendo, e tampouco o porquê, surpreendo-me hoje com a clareza das minhas escolhas metodológicas de então: tudo se passou como se tivesse tentado fazer da "participação" um instrumento de conhecimento. Nos encontros com os enfeitiçados e desenfeitiçadores, deixei-me afetar, sem procurar pesquisar, nem mesmo compreender e reter (Favret-Saada, 2005:157).
\end{abstract}

Também tive que deixei de lado, por algumas semanas, o meu projeto inicial de pesquisa para poder mergulhei na intensidade da experiência proposta pela residência. Identificar, classificar e analisar as questões relacionadas ao patrimônio cultural da cidade parecia não mais fazer sentido. Naquele momento, meu interesse etnográfico e artístico voltou-se para outra direção, para os elementos que estavam na superfície do lugar, para o que poderia surgir da relação entre as intervenções artísticas e o lugar.

\title{
As ações
}

Na segunda semana da residência, a proposta era a observação no Largo do Rosário. Conversamos com os moradores, visitamos suas casas, seus quintais, observamos os fluxos do cotidiano e as linhas que compunham o lugar. Fomos contaminados pelas forças que estavam presentes no Largo, suas formas, texturas e pelo fluxo daqueles que transitam e habitam o Largo. No final dessa semana de trabalho, construímos uma espécie de mapa com os principais afectos de cada artista, uma plataforma sensível de percepções perante o lugar. Alguns desses afectos eram comuns há alguns artistas, o que levou o grupo a ficar mais atento para eles, pois a repetição nos informava que ali havia forças geradoras de sensibilidade coletiva.

Por fim, com o mapa em mãos, na terceira semana, começamos a pensar coletivamente como poderíamos transformar os afectos em ações. Como a falta de árvores poderia criar sensações sobre o vazio? Como as janelas poderiam gerar encontros e sensações de isolamento e de liberdade? Como os caminhos, as linhas inscritas pelo fluxo das pessoas que atravessam o Largo, poderiam falar sobre os vestígios que nele duram? Outro desafio do coletivo era o da utilização dos materiais que existiam no Largo do Rosário, pois acreditávamos que assim conseguiríamos tornar 
sensível àquilo que supostamente passa despercebido no cotidiano daqueles que povoam o Largo.

\section{Abrir Janelas e Semear Encontros}

Perante as janelas do Largo do Rosário alguns afectos coletivos surgiram. As janelas coloniais existentes no Largo formam linhas que conectam as faixadas das casas, porém, apenas um muro não possuía janelas, fugindo da estética arquitetônica colonial que predominava no local. Também observamos que, no Largo do Rosário, as janelas quase sempre estavam fechadas, o que causou em alguns dos artistas a sensação de isolamento e em outros a de liberdade.

O centro histórico de Rio de Contas é atrativo por que as portas e as janelas dão para a rua, isso remeta a uma ideia de liberdade, é esteticamente interessante, é bom para se viver e sentir. Já fora do centro histórico, Rio de Contas é como qualquer outro interior do Brasil (Artista participante da Residência).

Particularmente, para esse artista que participou da residência, as janelas do Largo provocavam em seu corpo a sensação de liberdade. Porém, essa sensação existia somente no perímetro urbano tombado, ou seja, fora da arquitetura colonial as janelas não causavam essa sensação, era como em qualquer outro interior do Brasil. Durante a semana em que observamos o Largo do Rosário, também percebemos que as janelas eram pouco abertas pelos moradores, algumas nunca eram abertas e outras permaneciam abertas por curtos períodos de tempo.

Após o mapeamento desses afectos, partimos para a elaboração das ações. A Ação 0: abrir janelas e a Ação 1: semear encontros, surgiram dessa relação entre as janelas do Largo, as sensações dos artistas e a interação com os moradores do lugar. Nas ações, buscávamos compor uma tensão entre liberdade e isolamento, dentro e fora, colonial e contemporâneo.

Realizamos primeiramente a Ação 0 e reproduzimos, na única parede cega existente no Largo, o padrão de janelas do entorno. Pintamos durante a madrugada com tinta branca, um stencil reproduzindo três janelas coloniais no único muro do Largo do Rosário que não havia janelas. Na manhã seguinte a paisagem estava sutilmente transformada. As pessoas que transitavam pelo Largo aparentemente estranhavam aquela mudança, observavam e seguiam seus trajetos. 
Para a realização da ação, precisamos pedir a autorização do dono do imóvel e do IPHAN, pois se tratava de uma mudança na paisagem patrimonializada do perímetro tombado da cidade. A condição para a liberação da ação foi a de que o muro fosse pintado na cor original após o encerramento do projeto. Com a Ação 0, a tensão entre as proibições perante as mudanças nas fachadas das casas patrimonializadas protegidas pelas agências reguladoras do patrimônio, emergiram. Mas o que reproduzimos no muro foram janelas do estilo colonial, ou seja, criamos um dialogo estético com o que já estava posto no Largo. Porém, não se tratavam de janelas autenticas, eram reproduções que causavam fissuras na autenticidade da paisagem composta pelos monumentos que ali duravam.

Já na Ação 1: semear encontros, a proposta era provocar uma situação de encontros de olhares entre vizinhos, por meio da abertura das janelas. Convidamos os moradores do Largo do Rosário a abrirem suas janelas em dia e hora determinados. Confeccionamos convites com a seguinte mensagem: "Amanhã, ás 16:30h, abra a sua janela para o Largo do Rosário! Contamos com a sua participação!”. Na véspera da ação, passamos por todas as casas que cercam o Largo entregando o convite impresso e reforçando oralmente o convite.

No dia seguinte, ás 16:30h, as primeiras janelas começaram se abrir. A sensação era de expectativa por parte dos moradores, todos aguardavam um acontecimento, uma performance que supostamente seria produzida por nós e deveria ser assistida por eles nas janelas. O tempo foi passando e nada acontecia além do encontro de olhares entre os moradores do Largo e o aumento da expectativa em relação a um acontecimento outro. Por volta das $17 \mathrm{~h}$ algumas janelas foram fechadas, a expectativa em relação a uma performance nossa também foi diminuída. O sol foi entrando pelas montanhas, a noite foi chegando e a ação 1 encerrou-se quando o último morador do Largo fechou a sua última janela.

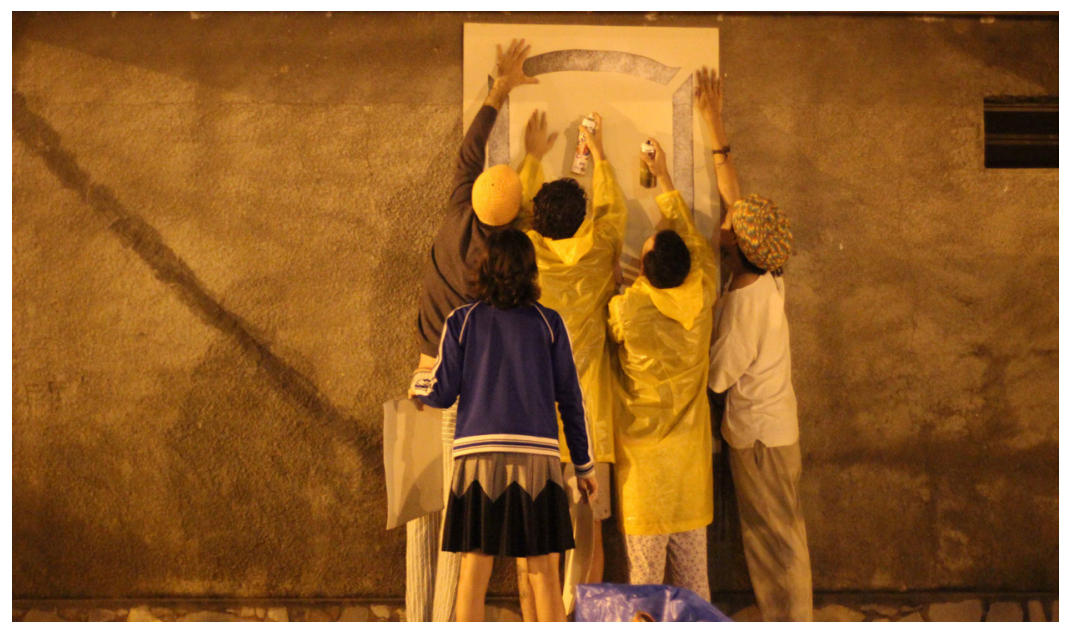




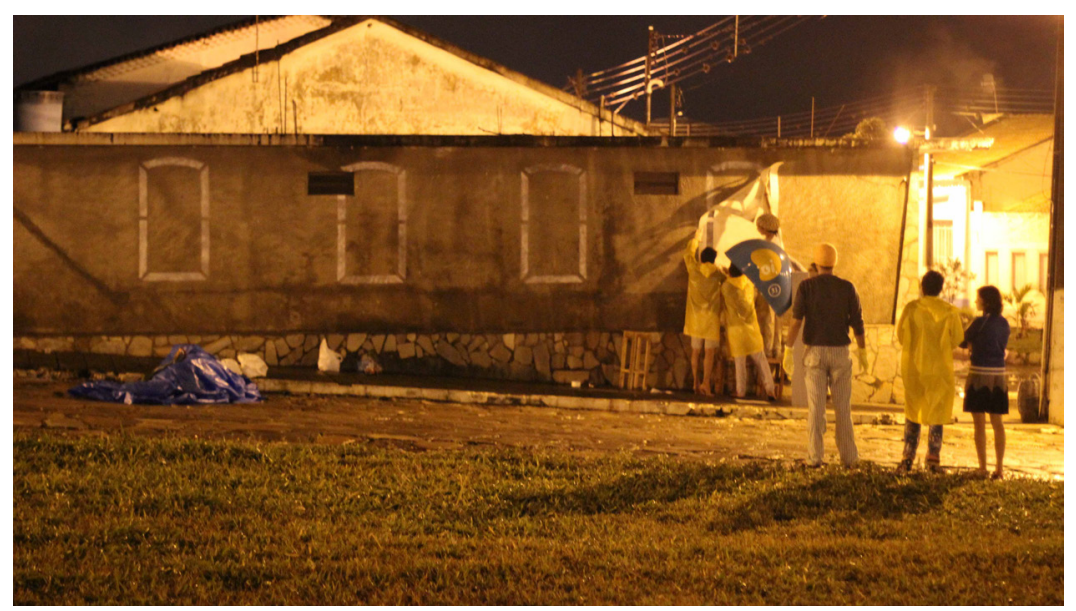

Figura 1: realização da Ação: 0 no Largo do Rosário. Fonte: arquivo pessoal.
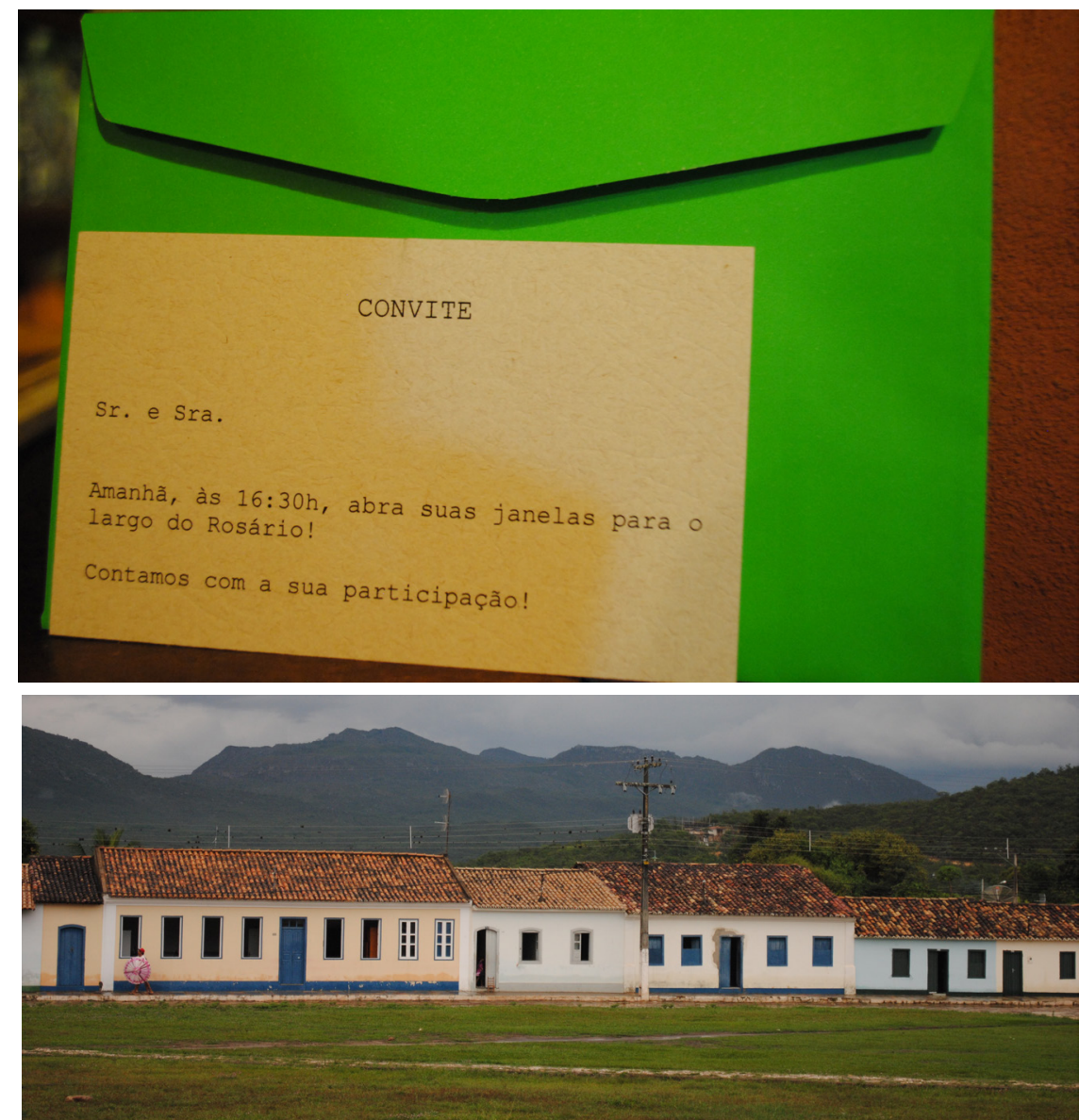

Figura 2: realização da Ação: 1 no Largo do Rosário. Fonte: arquivo pessoal.

\section{Cultivar Caminhos}


O Largo do Rosário é atravessado por um emaranhado de caminhos, alguns pavimentados com pedras, outros formados na grama pelo caminhar frequente daqueles que criam seu próprio trajeto. No gramado, encontramos diversos vestígios materiais deixados pelos que transitam nesse lugar. A ação 2 surgiu desse afeto, do desejo de pôr em evidência as sensações daquilo que foi descartado no Largo, o que estava em sua superfície, mas não era visto. Porém, observamos que nem sempre os trilhos, sejam eles de terra, ou os pavimentados com pedras, são escolhidos como itinerários pelas pessoas que transitam pelo Largo.

Fazer "aparecer às coisas" que ali estavam soterradas, produzir uma arqueologia da superfície, da pele do Largo do Rosário. Esse afecto coletivo surgiu principalmente perante os objetos inusitados que encontramos no gramado do Largo. Resto de fogos, chiclete, palitos, cigarros, ninhos de passarinhos, esterco de cavalo, latas de cerveja, ossos de animais, cd's, entre outros objetos, habitavam a superfície do Largo e nos davam pistas sobre os itinerários e os acontecimentos que ocorriam naquele lugar.

Em relação aos caminhos, decidimos criar revés nas rotas executando a Ação 2: cultivar caminhos. Coletamos os vestígios deixados no Largo do Rosário e os ordenamos sobre os caminhos de terra, sugerindo a criação de novos trajetos por aqueles que transitavam pelo Largo do Rosário. Os materiais coletados ordenados nos caminhos de terra criaram uma estética que pouco ornava com a paisagem das edificações históricas. Alguns moradores sentiram a Ação 2 como um protesto de viés ambientalista, que estava preocupado em evidenciar o "lixo" não recolhido da grama do Largo. De todo modo, a Ação 2 consegui produzir blocos de sensações perante os moradores que cruzaram o seu caminho com o caminho dos vestígios ordenados.

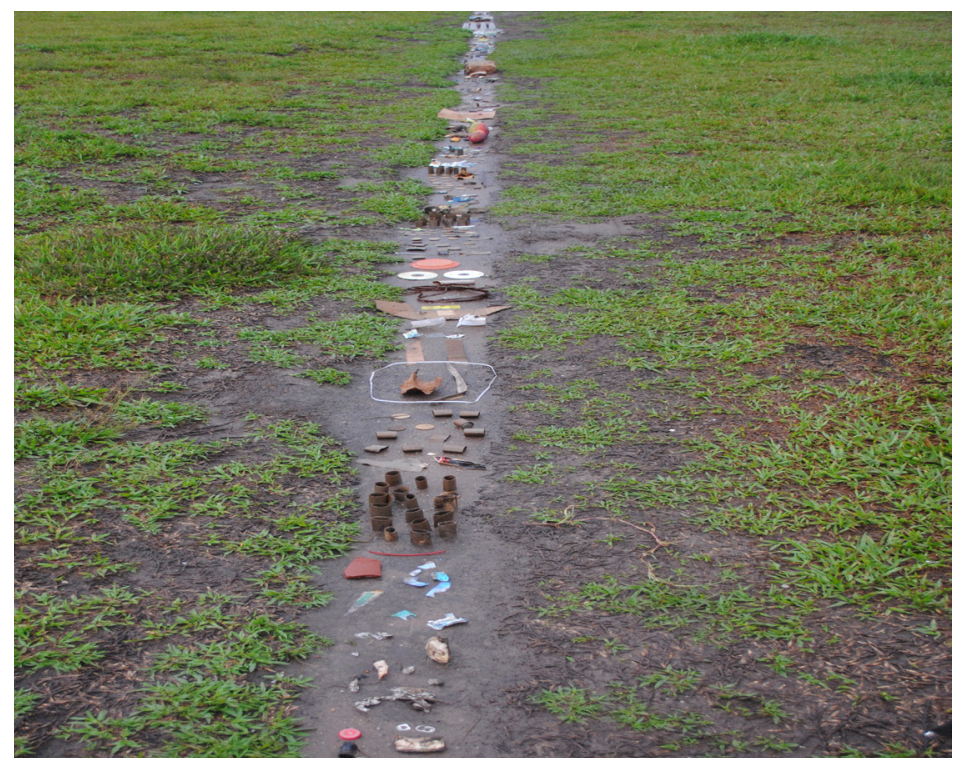




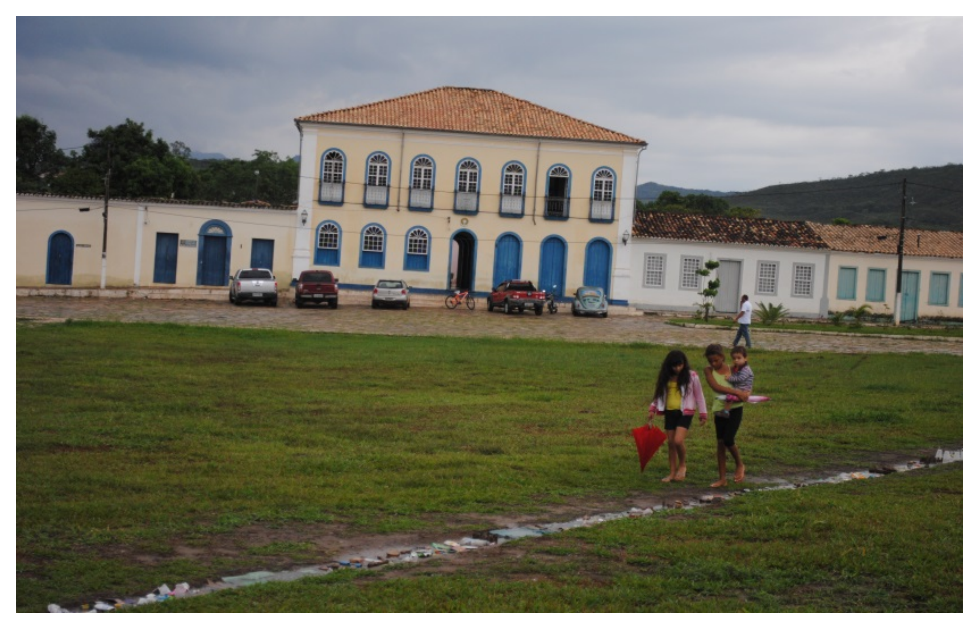

\section{Regar o mistério, plantar o possível e colher suspiros}

Dos afectos coletivos que surgiram no encontro entre o grupo de artistas e o Largo do Rosário, talvez o relacionados a derrubada das árvores tenha sido o mais potente. Três ações resultaram desse afecto: a Ação 3: regar o mistério; a Ação 4: plantar o possível e a Ação 5: colher suspiros. Todas essas ações surgiram da tentativa de se produzir sensações relacionadas a falta de árvores no grande descampado do Largo.

Atualmente, o IPHAN impede o plantio de novas árvores no Largo do Rosário, justificando essa proibição pelo tombamento do conjunto arquitetônico da cidade. Nesse sentido, percebemos que essa interdição nos afetou principalmente perante a dicotomia natureza/cultura que ali estava sendo colocada pela agência reguladora do patrimônio. Nessa dicotomia, natureza e cultura são tratadas como totalidades ontologicamente distintas, onde o mundo da cultura (patrimônio) seria mais importante mundo da natureza (árvores).

Partimos então para a criação de ações que pudessem criar sensibilidades perante essa tensão entre o patrimônio cultural edificado e a falta de árvores no Largo do Rosário. Apenas uma palmeira resiste no Largo, ela existe solitariamente em frente o prédio da Prefeitura Municipal de Rio de Contas. Como já mencionado anteriormente, observamos durante alguns dias e noites os fluxos cotidianos do Largo do Rosário. Nesse momento da observação percebemos que a luz de um poste público produzia uma grande sombra noturna dessa palmeira que atravessava o Largo. Assim surgiu a Ação 3: 
regar o mistério, que consistiu em então demarcar com cal a sombra noturna dessa última árvore.

Na Ação 4: plantar o possível, seguimos no afeto das árvores e convidamos os moradores do Largo do Rosário a deixar, por um tempo determinado, vasos de plantas do seu jardim no gramado do Largo. Habitamos novamente o lugar com plantas, mudando provisoriamente a paisagem.

O Largo do Rosário é coberto em algumas partes por flores cor de rosa da família das sempre-vivas, nomeada localmente como Suspiro. Essas flores são de uma espécie endêmica, ou seja, desenvolvem-se estritamente nessa região. Desse afeto, surgiu a Ação 5: colher cuspiros. A proposta era criar mais possibilidades de relação entre os moradores da cidade com essas flores. Assim, amarramos cartões cor de rosa com frases de amor nos suspiros e convidamos os moradores de Rio de Contas a colhêlos.

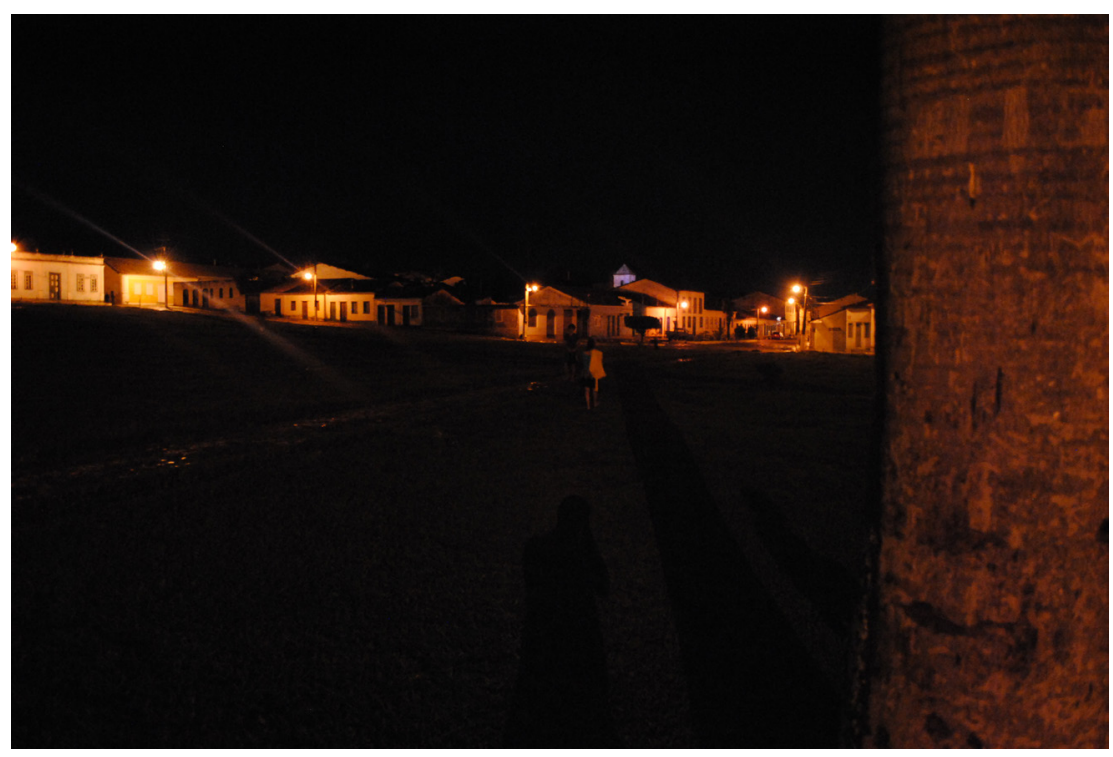




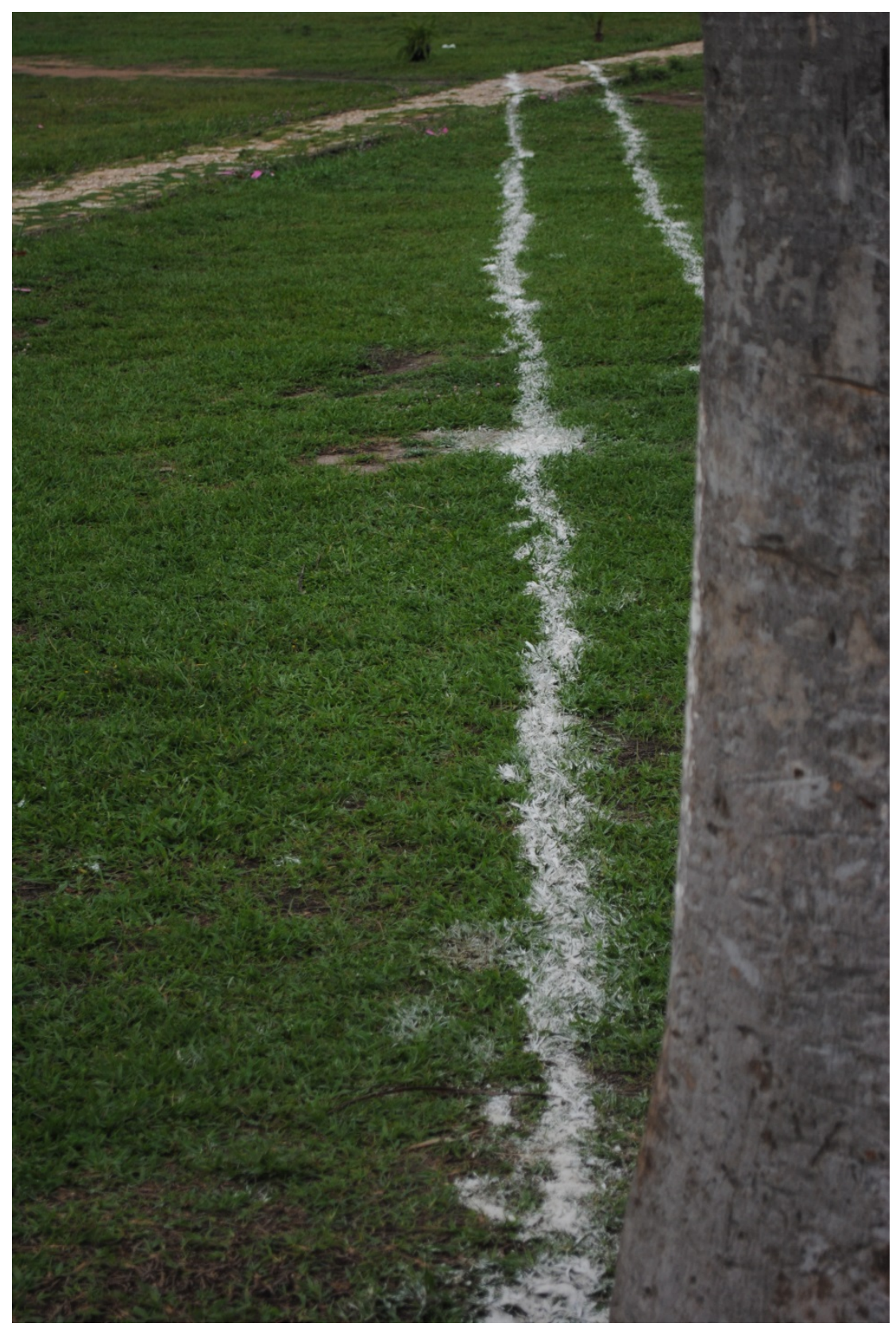

Figura 3: realização da Ação: 3 no Largo do Rosário. Fonte: arquivo pessoal. 

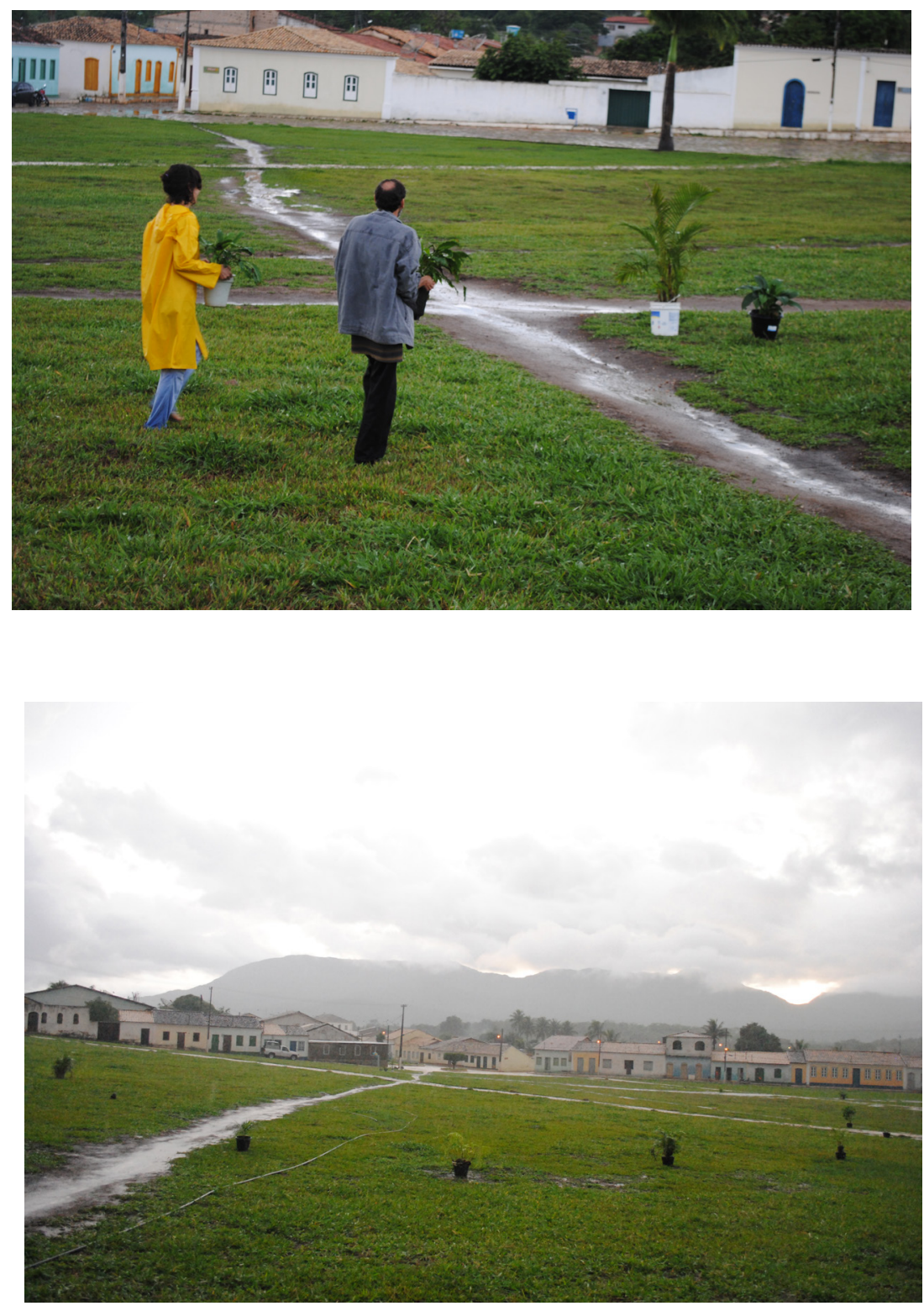

Figura 4: realização da Ação: 4 no Largo do Rosário. Fonte: arquivo pessoal. 


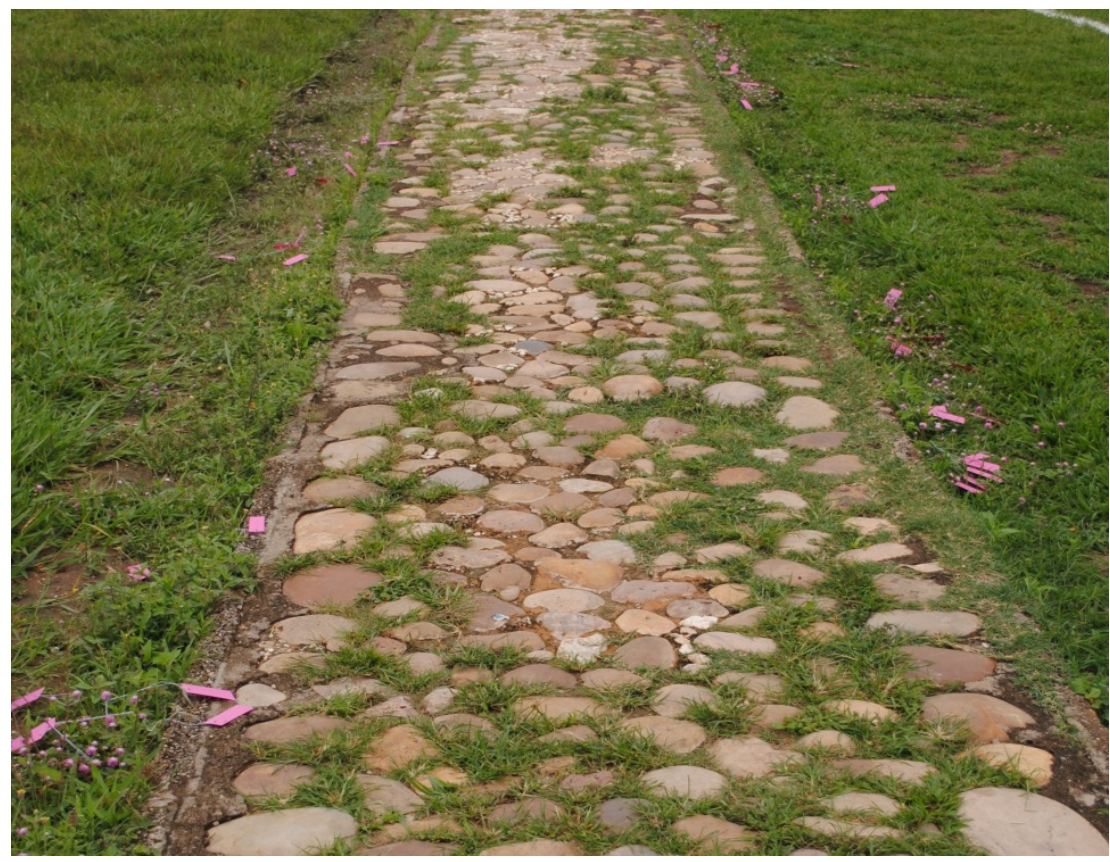

Figura 5: realização da Ação: 5 no Largo do Rosário. Fonte: arquivo pessoal.

\section{A exposição: Largo Jardim - O que tem este lugar?}

Como forma de partilhar o processo vivenciado durante a residência, construímos a exposição Largo Jardim - O que tem este lugar?. Além dos vídeos, sons, fotografias e materiais utilizados nas ações do Largo Jardim, convidamos os moradores da cidade para deixarem suas impressões sobre o Largo do Rosário e sobre as ações da residência. Na abertura da exposição, na noite do dia 28 de janeiro de 2013, no Espaço Imaginário, promovemos também uma roda de conversa entre os participantes do projeto e o público presente.

Apenas uma moradora do Largo do Rosário compareceu, não permanecendo lá por muito tempo. Porém, moradores de outros bairros da cidade visitaram a exposição. O que foi exposto no Espaço Imaginário não foram "obras" do grupo em si, mas apenas o registro das ações que realizamos no Largo do Rosário durante o período da residência artística. Talvez a distancia do público em relação à arte contemporânea tenha causado a sensação de que o que estava ali exposto não tinha muita importância e que algum tipo 
de "apresentação" aconteceria depois. Aos poucos, as pessoas foram chegando e a roda de conversa começou.

No debate, discutimos as ações realizadas pelo coletivo. Apenas uma pessoa se manifestou nesse momento, questionando a fugacidade das ações. "Parece que nada ficou pra cidade, o produto de vocês é difícil de ser visualizado (P.Q)”. Também fomos questionados por esse morador da cidade em relação a pouca utilização da história e da memória do lugar nas ações: "vocês têm ciência de que naquele lugar já existiu uma igreja, uma lagoa? (P.Q)". Achei oportuno alimentar alguns questionamentos nesse momento, e respondi com outra pergunta, com o intuito de instigar o debate em torno da memória e do patrimônio em Rio de Contas: "por que deveríamos utilizar a memória e a história nas ações?” Ele respondeu:

\footnotetext{
Se era simplesmente para utilizar a cidade como um vazio, poderíamos ter escolhido um campo de futebol, ou um bairro fora do centro histórico da cidade para a realização das ações, que deveríamos ter um pouco mais de preocupação em dar identidade para as pessoas da cidade, em explorar a beleza e a exclusividade da paisagem do centro histórico da cidade (Morador da cidade presente na exposição).
}

Fiquei reflexivo após essa fala, sabia que ali, naquela arena, havia vindo à tona uma dos sentidos atribuídos ao patrimônio cultural em Rio de Contas. Neste momento, a eletricidade caiu, a cidade inteira ficou às escuras, o silêncio se instalou e a roda de conversa da abertura da exposição do Largo Jardim foi encerrada.

Segui pensando sobre o que esse morador queria dizer com a "exclusividade do centro histórico de Rio de Contas?" e sobre a impressão que ficou de que utilizamos a cidade como um vazio - questões me acompanharam por algum tempo. De certa forma, os afectos dos artistas participantes da residência também foram tangenciados pela estética da cidade, porém nenhuma ação foi construída com base em uma excepcionalidade nela presente.

Mas de que estética, na visão desse morador, precisaríamos nos apropriar para a construção de identidades em que uma suposta singularidade do centro histórico da cidade fosse valorizada? O que pode ser percebido com a fala desse morador é a presença de uma subjetividade em relação à qual o patrimônio cultural da cidade, o acontecido, é tido como a maior força que ainda habita esse lugar. As ações, ao sugerir outras possibilidades de interagir com os elementos presentes na cidade, parecem ter causado uma espécie de desterritorialização, de desarranjo das identidades construídas, que foram imediatamente acionadas para sustentar um plano seguro: aquele onde a 
cidade já aconteceu, mantendo-se fechada para a criação de novas formas de povoamento do espaço urbano e de novas sensibilidades na relação com o Largo do Rosário.

Com as ações, identidades alternativas ao patrimônio cultural de Rio de Contas emergiram. Como já mencionado anteriormente, o patrimônio cultural representa alegoricamente valores de excepcionalidade, de autenticidade e de relevância histórica, e também pode representar uma poderosa narrativa sobre a identidade nacional, ou de um grupo. Mas quando essa identidade começa a sofrer fissuras o que também está em jogo? Certamente a própria ideia de unidade e de homogeneidade cultural.

O Largo Jardim não foi um ato heroico, os artistas não estavam ali com o intuito de quebrar as noções essencialistas em relação a um patrimônio cultural que supostamente representaria toda a cidade. Muitos nem estavam ali interessados nessas questões especificas. Porém, na experiência coletiva entre artistas, moradores e a cidade, talvez tenha sido a primeira vez em que o patrimônio cultural local não foi tratado como algo simplesmente excepcional, que narra uma história oficial que deve ser tida como a mais verdadeira e que por isso deve ser preservado.

Linhas de fuga em relação a esse achatamento histórico ganharam força com as ações. Árvores ressurgiram no largo, janelas brotaram nos muros, vizinhos se olharam, caminhos seguros foram obstruídos pelos vestígios decantados e silenciosos daquele aparente campo vazio. Um pequeno exercício, mas que produziu efeito sobre as ideias e os monumentos cristalizados que habitam a cidade de Rio de Contas.

\section{Considerações Finais}

As questões em torno da relação entre as políticas de patrimônio cultural, a perspectiva pós-colonial e o uso metodológico de práticas artísticas na pesquisa etnográfica foram às balizas com as quais esse trabalho se direcionou. Porém, com o intuito de criar uma perspectiva que fugisse das noções hegemônicas de patrimônio cultural, as experiências artísticas e etnográficas vivenciadas no Largo Jardim foram narradas não no sentido da descrição de uma sociedade ou período histórico, mas de uma releitura das formas de habitar o Largo do Rosário decentralizada das narrativas imperiais do passado. 
Certamente as políticas de patrimônio cultural contribuam para a duração de uma memória e das estruturas de poder colonial que ainda habita essa cidade. Mas o patrimônio cultural também pode ser utilizado como uma plataforma discursiva onde os moradores das cidades patrimonializadas se apropriem material e simbolicamente dessas edificações na composição de outros usos e sentidos possíveis para a existência no presente. $\mathrm{O}$ espaço da tradição, imutável e estagnado, é inofensivo por não produzir diferença nas estruturas de poder vigentes; suas bordas já são conhecidas e estão assimiladas pela ilusão da integração e igualdade em estruturas sociais onde as relações simbólicas ainda estão infestadas pela logica colonial. 


\section{Referências}

DELEUZE, G.; GUATTARI, F. O que é a filosofia? Trad. Bento Prado Jr. e Alberto Alonso Muñoz. Rio de Janeiro: Ed. 34, 1992.

DURAND, Gilbert. As estruturas antropológicas do imaginário. Trad. Hélder Godinho. Lisboa: Presença, 1997/2007.

ECKERT, Cornelia; ROCHA, Ana Luiza Carvalho da. A cidade e suas crises, o patrimônio pelo viés da memória: por que e como preservar o passado? Habitus, Revista do Instituto Goiano de Pré-Historia e Antropologia da Universidade Católica de Goiás, v. 4, n.1, p. 455-470, jan./jun. 2006.

EUGENIO, Fernanda; Fiadeiro, João. Secalharidade como ética e como modo de vida: o projeto And_Lab e a investigação das práticas de encontro e de manuseamento coletivo do viver juntos. Urdimento, Florianópolis, v. 19, p. 61-69, 2012.

FAVRET-SAADA, J. Ser afetado. Trad. Paula de Siqueira Lopes. Cadernos de Campo, n. 13, p. 155-161, 2005.

GIBSON, James J. The ecological approach to the visual perception of pictures. Leonardo Journal, v. 11, n. 3, p. 227-35, 1978.

GONÇALVES, José Reginaldo Santos. A Retórica da Perda: os discursos do patrimônio cultural no Brasil. Rio de Janeiro: Ed. da UFRJ; IPHAN, 1996.

GUARANÁ DE CASTRO, E. Estudos de Comunidade: reflexividade e etnografia em Marvin Harris. Revista Universidade Rural, v. 23,n. 2, p. 195-210, 2001.

HALBWACHS, Maurice. A Memória Coletiva. São Paulo: Centauro, 2006.

HARRIS, Marvin. Town and Country in Brazil. New York: Columbia University Press, 1956.

LIMA FILHO, Manuel Ferreira. Da matéria ao sujeito: inquietação patrimonial brasileira. Revista de Antropologia da USP, São Paulo, v. 52, n. 2, p. 605-632, jul.-dez. 2009.

PIEROTE SILVA, Jean Pierre. Deslocamentos Patrimoniais: polifonias, memórias e visualidades em Rio de Contas (BA). 2014. Dissertação (Mestrado em Antropologia Social) - Universidade Federal de Goiás, Goiânia, 2014.

RIEGL, Aloïs. O culto moderno dos monumentos, sua essência e sua gênese. Trad. Elaine Ribeiro Peixoto e Albertina Vicentine. Goiânia: UCG, 2006.

TAMASO, Izabela. Em nome do Patrimônio: Representações e Apropriações da Cultura na Cidade de Goiás. 2007. 787 f. Tese (Doutorado em Antropologia Social) Universidade de Brasília, Brasília, 2007. 